Review Article

\title{
A Novel Method of Increasing Medical Student Nutrition Awareness and Education
}

\author{
Cynthia L. Schoettler, ${ }^{1}$ Jennifer N. Lee, ${ }^{1}$ Kathy A. Ireland, ${ }^{1,2,3}$ and Carine M. Lenders ${ }^{1,2,3}$ \\ ${ }^{1}$ Boston University School of Medicine, Boston, MA 02118, USA \\ ${ }^{2}$ Nutrition and Fitness for Life Program, Department of Pediatrics, Boston Medical Center, Boston University School of Medicine, \\ Boston, MA 02118, USA \\ ${ }^{3}$ Department of Pediatrics, Division of Pediatric Nutrition, Boston Medical Center, Boston University School of Medicine, \\ Boston, MA 02118, USA
}

Correspondence should be addressed to Cynthia L. Schoettler; cynthia.schoettler@gmail.com

Received 15 November 2014; Accepted 11 January 2015

Academic Editor: Sumantra Ray

Copyright (C) 2015 Cynthia L. Schoettler et al. This is an open access article distributed under the Creative Commons Attribution License, which permits unrestricted use, distribution, and reproduction in any medium, provided the original work is properly cited.

\begin{abstract}
Medical nutrition education in most US medical schools is lacking, despite an epidemic of lifestyle related chronic conditions and high rates of malnutrition in hospitals. In a unique response to this deficit, students at Boston University School of Medicine have created a novel student interest group entitled Student Nutrition Awareness and Action Council (SNAAC). This student group is unique in that it focuses on interprofessional collaboration and development of concrete practice skills and works to fill educational gaps. The goal of SNAAC is to increase medical student knowledge, attitude, and skills in medical nutrition through providing extracurricular activities and partnering with official medical school curriculum committees. To accomplish this, SNAAC has developed a multipartite group overseen by a mentoring team composed of a physician nutrition specialist, registered dietitian, and a mental health provider. SNAAC provides nutrition oriented opportunities for members and the student body at large. Participation is high because it fills an educational gap, offers a unique focus on expanding nutrition awareness and education, and provides opportunities for student leadership and professional development. We encourage other medical schools to use the SNAAC student involvement model to increase nutrition awareness and facilitate the incorporation of medical nutrition in their curriculum.
\end{abstract}

\section{Introduction}

Nutrition education in medical school, residency and subspecialty medical training is inadequate despite the high prevalence of hospital malnutrition (40-60\%) [1] and evidence that nutrition interventions reduce morbidity and mortality [25]. Obesity is also highly prevalent and has been identified as the second leading cause of preventable death in the United States [1]. Appropriate knowledge of nutrition is necessary to prevent and treat nutrition conditions from the hospital to the community setting. The United States Preventative Services Task force urged physicians to counsel their patients regarding nutrition and weight management to fulfill the recommendations for 2010 [2]. Therefore physicians graduating from medical school and residency should be able to provide anticipatory nutrition guidance, identify and assess patients at nutrition risk, and refer them appropriately to a dietitian or a multidisciplinary team that includes a dietitian. These skills represent the first step to improving nutrition-related health outcomes, length of hospital stay and cost of care [6].

Despite these recommendations, physician lifestyle counseling declined from $7.8 \%$ to $6.2 \%$ of all visits from 1995 96 to 2007-08 [7]. The most common barriers stated by primary care physicians to providing nutrition counseling included knowledge deficits, inadequate resources, lack of time, and poor compensation [8]. The knowledge gap is attributed largely to a lack of nutrition education and training in the medical school curriculum. Currently, undergraduate medical nutrition education focuses primarily on the basic scientific understanding of metabolism and vitamin deficiencies, but does not translate into direct patient care and is not driven by current standards of clinical practice. 


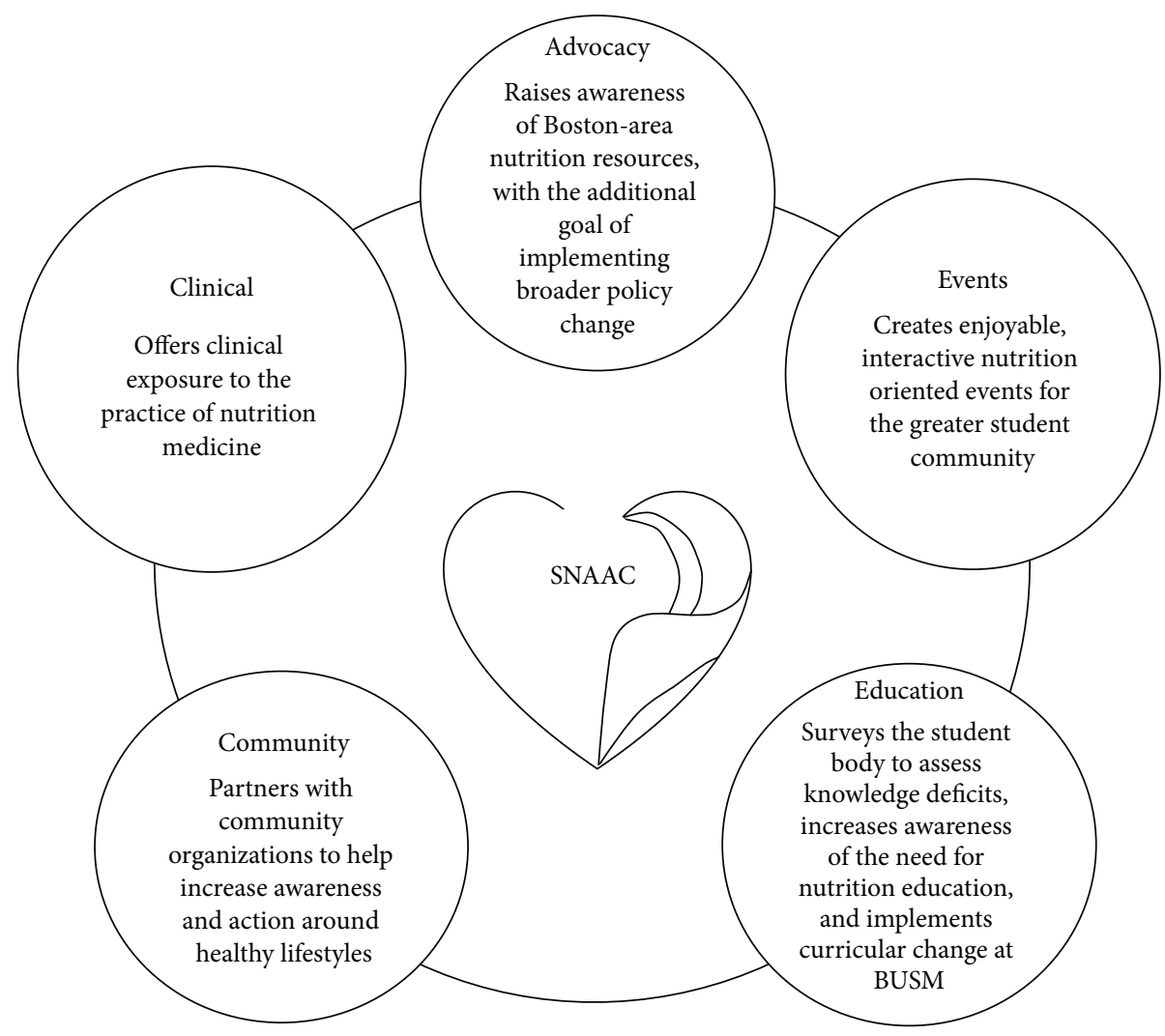

FIGURE 1: Group structure of SNAAC.

Medical students are aware of this deficit, and frequently express a desire for increased nutrition education in the curriculum [9-11]. To address the need for curricular change at Boston University School of Medicine (BUSM), motivated students created a student-run nutrition interest group entitled the Student Nutrition Awareness and Action Council (SNAAC). The purpose of this paper is to describe the group's composition and experiences in offering nutrition focused extracurricular learning opportunities and curricular change in hope of demonstrating how student-led interest groups following the SNAAC model can be a vehicle for nutrition advocacy in medical schools.

\section{Multifaceted Group Structure}

The Student Nutrition Awareness and Action Council (SNAAC) was founded in 2009 by two medical students. The primary goal of this group is to improve medical student understanding of nutrition and obesity medicine using extracurricular service-learning projects. Other goals include teaching students how to assess nutritional status and equip them with counseling techniques to treat patients at nutritional risk, as well as creating a base of interested students to advocate for broader nutrition education change. As opposed to the more typical single focus student interest groups, SNAAC has opted for a multifaceted approach that encompasses five key areas (Figure 1, group structure of SNAAC).
Like other student interest groups, two student co-chairs lead the group, but each of the five key areas has an additional dedicated student leader. Another unique feature of SNAAC is the support it gets through a multidisciplinary mentoring team rather than from one advisor. This mentoring team is composed of three faculty members: a physician nutrition specialist, a registered dietitian, and a licensed clinical social worker. When founded in 2009, the group consisted of two students. By the 2012 academic year, there were an average of 29 active members and around 100 participants in SNAACsponsored events annually.

The multifaceted approach allows for multiple activities to occur during the same academic year and attracts students with a variety of interest and skills that complement each other. Highlights from the 2012 academic year include the introduction of two new events aimed at increasing medical student awareness of challenges faced by the underserved populations served by Boston Medical Center (BMC) and surrounding network of community health centers. One event is the "Supplemental Nutrition Assistance Program (SNAP) challenge," where students volunteered to limit their weekly grocery spending to the average Massachusetts SNAP benefit for an individual and journal their experience. The other event is the "Test Kitchen," a partnership with Boston Medical Center's (BMC) state-of-the-art demonstration kitchen to familiarize medical students with nutrition resources and skills through attending cost-conscious healthy 
TABLE 1: Compilation of SNAAC activities over the 2012-2014 academic years.

\begin{tabular}{|c|c|c|c|}
\hline Event & Branch & Description & Participants \\
\hline SNAP challenge & Advocacy & $\begin{array}{l}\text { Students challenged to limit their grocery } \\
\text { spending to } \$ 33 / \mathrm{wk} \text {, the average MA SNAP } \\
\text { benefit for an individual }\end{array}$ & 17 medical students since 2012 \\
\hline Test Kitchen & Advocacy & $\begin{array}{l}\text { Familiarizing medical students with nutrition } \\
\text { resources and skills through attending } \\
\text { cost-conscious healthy cooking demos }\end{array}$ & 24 medical students since 2012 \\
\hline $\begin{array}{l}\text { Nutrition for Life } \\
\text { (NFL) Clinic } \\
\text { observation }\end{array}$ & Clinical & $\begin{array}{l}\text { Providing medical students with early exposure } \\
\text { to outpatient specialty multidisciplinary } \\
\text { pediatric weight management }\end{array}$ & $\begin{array}{l}\text { Approximately } 30 \text { medical students since } \\
2010\end{array}$ \\
\hline $\begin{array}{l}\text { BMSCoN, } \\
\text { Nutrition } \\
\text { Lecture Series }\end{array}$ & $\begin{array}{l}\text { Community } \\
\text { outreach }\end{array}$ & $\begin{array}{l}\text { Creating a city-wide network of nutrition } \\
\text { oriented medical students to increase } \\
\text { networking and nutrition education resources }\end{array}$ & $\begin{array}{l}4 \text { BUSM students active in leadership, } \\
\text { attendance of } \sim 20 \text { BUSM students per } \\
\text { lecture. } 7 \text { other Boston medical students } \\
\text { from Tufts and Harvard also active in group } \\
\text { leadership }\end{array}$ \\
\hline $\begin{array}{l}\text { Wellness fair for } \\
\text { Spanish speaking } \\
\text { elders }\end{array}$ & $\begin{array}{l}\text { Community } \\
\text { outreach }\end{array}$ & $\begin{array}{l}\text { Provided nutrition counseling, education } \\
\text { materials, and healthy snack demonstration for } \\
\text { wellness fair attendees }\end{array}$ & $\begin{array}{l}4 \text { Spanish speaking SNAAC members } \\
\text { assisted in this collaborative project }\end{array}$ \\
\hline $\begin{array}{l}\text { Nutrition } \\
\text { module, 1st and } \\
\text { 2nd years }\end{array}$ & Education & $\begin{array}{l}\text { Incorporated } 2 \text { mandatory online modules into } \\
\text { the first and second year curriculums that focus } \\
\text { on taking a diet history and evaluating popular } \\
\text { diet trends, with the aim of increasing positive } \\
\text { attitudes to physician lifestyle counseling }\end{array}$ & $\begin{array}{l}\text { Mandatory participation of BUSM class of } \\
\text { approximately } 175 \text { students }\end{array}$ \\
\hline $\begin{array}{l}\text { Nutrition } \\
\text { module, 4th year }\end{array}$ & Education & $\begin{array}{l}\text { Aimed at students entering all specialties, this } \\
\text { will combine online instruction with in-class } \\
\text { practice of basic nutrition and behavioral } \\
\text { health counseling }\end{array}$ & $\begin{array}{l}\text { Mandatory for each BUSM } 4 \text { th year class, } \\
\text { approximately } 175 \text { students }\end{array}$ \\
\hline $\begin{array}{l}\text { Orientation bus } \\
\text { tour }\end{array}$ & Education & $\begin{array}{l}\text { To introduce first year medical students to the } \\
\text { food and fitness environment of Boston } \\
\text { neighborhoods during the orientation bus tour }\end{array}$ & $\begin{array}{l}4 \text { SNAAC members participated in the } \\
\text { orientation, which was attended by } 175 \text { 1st } \\
\text { year BUSM students at the start of medical } \\
\text { school }\end{array}$ \\
\hline DI/MS match & Events & $\begin{array}{l}\text { Pairing dietetic interns and medical students to } \\
\text { share knowledge and build interdisciplinary } \\
\text { approaches to healthy lifestyle counseling }\end{array}$ & $\begin{array}{l}57 \text { medical students and } 57 \text { dietetic interns } \\
\text { since } 2010\end{array}$ \\
\hline Walk for hunger & Events & $\begin{array}{l}\text { Raising awareness of food insecurity by } \\
\text { participating in the Boston-wide event }\end{array}$ & 10 students \\
\hline Lunch talks & Events & $\begin{array}{l}\text { Providing educational, nutrition-focused talks } \\
\text { that will meet a wide range of interests in the } \\
\text { medical student body }\end{array}$ & $\begin{array}{l}\text { Attendance of around } 25-50 \text { medical } \\
\text { students per lecture; } \sim 4 \text { lectures per } \\
\text { academic year }\end{array}$ \\
\hline
\end{tabular}

cooking classes. Both activities enhance student understanding and empathy for the population they serve and give them concrete skills to draw upon. As a result, their confidence and ability to counsel patients regarding healthy lifestyles increase. For a more complete listing of SNAAC's accomplishments, please see Table 1: Compilation of SNAAC activities over the 2012-2014 academic years.

\section{Multidisciplinary and Interprofessional Approach}

SNAAC is also set apart by its efforts to increase communication and collaboration across professions. In light of the current movement in education reform, the Association of American Medical Colleges (AAMC) has provided recommendations to implement interprofessional education and collaborations in order to enable future physicians to provide better team care and reduce error [12-14]. There is increasing evidence that interprofessional collaboration helps students understand their role and that of others in the health care team [15], thus improving care. In fact, Karnieli-Miller agrees that experiences of communicating and working within teams are the best method for learning about professionalism [16].

Unique to SNAAC is the dietetic intern/medical student (DI/MS) match. Through this program, students are able to work one-on-one with dietetic interns, a unique opportunity for many future physicians. Dietetic interns counsel medical students about their diet and lifestyle habits and share information about nutritional management of disease. Medical students share their knowledge in medical assessment and drug treatments of disease. One of the activities includes a trip to the grocery store, where students learn to better understand food access issues, read labels, and be smarter 
consumers. Since its creation in 2010, there have been more than one hundred student participants in the DI/MS match. Medical students have reported gaining a better understanding of the important role that dietitians play in the health care system, a finding observed in other interprofessional student activities $[17,18]$. In an era where health care is increasingly team based and multidisciplinary, these are valuable lessons for future clinicians.

SNAAC has also been instrumental in providing early clinical exposure to a team-based approach to weight management. This is done by providing all first and second year students the opportunity to observe a family-centered team approach to pediatric obesity at the Nutrition and Fitness for Life (NFL) clinic at BMC. During the clinical visit, a team comprised by a physician nutrition specialist, a registered dietitian, and a licensed social worker conduct a medical, dietary, and mental health assessment of an obese child or adolescent and provide a comprehensive treatment plan. The faculty advisors of SNAAC offer an Elective in Advanced Pediatric Nutrition, open to all fourth year medical students, which provides more team-based opportunities in both the inpatient and outpatient setting.

More recently, SNAAC has partnered with other nutrition student interest groups from Tufts Medical School and Harvard Medical School to create the Boston Medical Students Committee on Nutrition (BMSCoN). Students have organized and attended city-wide lectures focusing on important nutrition topics. Notable area dietitians, physicians, and public health scientists have given the lectures, which meet the group's objective of increasing nutrition knowledge, awareness, and networks through interprofessional partnerships across the city. In addition to these educational events, BMSCoN sponsors one community event each year to increase student involvement in the community.

\section{Agent of Change and Sustainability}

One of the long-term goals for SNAAC is to encourage and help implement broader curricular change for medical students in nutrition medicine. Without a consistent nutrition curriculum, students and residents have been shown to develop less positive attitudes towards providing lifestyle counseling and report lower confidence in their counseling ability as their education continues [19, 20].

To address the need for curricular change at BUSM, the Nutrition Vertical Integration Group (VIG) was formed in 2007. The objectives of this collaboration between faculty and students from various departments are to assess the status of nutrition education, identify areas for improvement, integrate nutrition into the medical school curriculum, and enhance nutrition related clinical skills. The nutrition VIG model is centered on medical students to assess gaps, integrate medical nutrition, and sustain change. Since joining the VIG in 2009, SNAAC members have been essential in strengthening curricular change.

The alignment of SNAAC and the Nutrition VIG has allowed for more in depth assessment of the curriculum, leading to additional hours of nutrition in the medical school curriculum ranging from an introduction in the preclinical years to nutrition counseling in the fourth year curriculum. Currently, curriculum review and feedback from course directors indicates that BUSM offers about 27 hours of nutrition education throughout the preclinical curriculum and another 12 hours throughout mandatory rotations in the clinical curriculum (Table 2). While this meets the formal requirement of 25 hours of nutrition education set forth by the National Academy of Science [21], most of the hours of education are still found in the basic sciences, which do not directly inform the management of hospitalized patients and the lifestyle counseling skills required of modern physicians in clinical practice.

As active participants in the Nutrition VIG, SNAAC participants have addressed this deficit by helping to create a dietary self-assessment module, as well as adding cases and components to several introductory clinical courses. Most recently, a pilot education project of four hours of formal didactics about the dietary guidelines, basics of nutrition counseling, and practical approaches to prevention and treatment of obesity have been introduced into the preclinical biochemistry course. Mandatory online modules accompany the lectures, as well as optional readings that reinforce important concepts. In the 4 th year, a nutrition and health behavior counseling module is being piloted in the required ambulatory medicine block. As there are many factors that are subject to change when determining medical school curriculum, continual assessment of the efficacy of these interventions is needed.

\section{Professional Development}

Because of the multipartite group structure, there are more opportunities for student leadership and advocacy than most other medical student groups. Student leaders are continually gaining skills in communication, organization, grant applications, and sharing of ideas through presentations and manuscripts. The professional skills that student leaders are equipped with are invaluable and will be useful for the remainder of their professional careers in medicine.

Another area of professional development available to interested students is formal assessment of the efficacy of a given intervention. For example, members of SNAAC continue to actively assess the knowledge of the student body in order to affect curricular change. A student member and a dietitian faculty mentor from SNAAC recently conducted an electronic survey to assess the medical student body's knowledge and confidence to refer to dietitians and community resources across the four-year curriculum. Preliminary data from this survey was presented locally and at the Experimental Biology meetings of the American Society of Nutrition [22]. Further examples of students' professional accomplishments are listed in Table 3.

\section{Discussion}

Most examples of educational reform focus solely on educational change through formal curricular development and enhanced information-based modules. An example of this approach is Adams et al., who developed the Nutrition 
TABLE 2: Breakdown of the location of nutrition education at BUSM.

\begin{tabular}{|c|c|c|}
\hline Years $1 \& 2$ & Year 3 & Year 4 \\
\hline $\begin{array}{l}\text { Biochemistry includes medical nutrition } \\
\text { with a multidisciplinary approach }(6 \mathrm{~h}) \\
\text { Physiology includes lectures on appetite } \\
\text { regulation, fuel metabolism, diabetes, and } \\
\text { insulinoma ( } 3.5 \mathrm{~h}) \\
\text { Human Behavior in Medicine includes a } \\
\text { lecture on obesity \& eating disorders } \\
(1 \mathrm{~h}) \\
\text { Introduction to Clinical } \\
\text { Medicine includes a dietary intake } \\
\text { self-assessment module developed with an } \\
\text { RD (1h) } \\
\text { Introduction to Clinical Medicine has a } \\
\text { seminar on nutrition and cancer taught } \\
\text { by an RD } \\
\text { (40 minutes) } \\
\text { Disease \&Therapy: Endocrine covers } \\
\text { obesity, type } 2 \text { diabetes, Syndrome X and } \\
\text { popular diets, and modules developed } \\
\text { with an RD } \\
\text { (9h) } \\
\text { Disease \&Therapy: Gastroenterology } \\
\text { covers malabsorption and other GI } \\
\text { conditions (6h) }\end{array}$ & $\begin{array}{l}\text { Family Medicine rotation offers case } \\
\text { studies \& uses motivational interviewing } \\
\text { techniques }(3 \mathrm{~h}) \\
\text { Pediatrics core conference has a lecture } \\
\text { series on nutrition needs of children } \\
\text { during growth ( } 3 \mathrm{~h}) \\
\text { Obstetrics/Gynecology rotation requires } \\
4 \text { case-based learning topics (e.g., } \\
\text { prenatal care, diabetes) and includes a } \\
\text { module addressing patients' nutritional } \\
\text { assessment and access to food }(4 \mathrm{~h})\end{array}$ & $\begin{array}{l}\text { Nutrition Support in Clinical Practice } \\
\text { Elective includes nutrition support and } \\
\text { managing adult obesity } \\
\text { Advanced Pediatric Nutrition Elective } \\
\text { covers aspects of breastfeeding, } \\
\text { childhood obesity, failure to thrive, } \\
\text { community resources, and nutrition } \\
\text { support. } \\
\text { Pediatric Endocrine and Neonatal } \\
\text { Electives include work with an RD } \\
\text { Geriatrics rotation has a lecture on } \\
\text { primary prevention of osteoporosis (1 h) } \\
\text { Ambulatory a modulecovering basic } \\
\text { nutrition with a focus on type } 2 \text { diabetes, } \\
\text { obesity, and health behavior counseling } \\
\text { (1 h) }\end{array}$ \\
\hline
\end{tabular}

TABLE 3: List of major accomplishments by SNAAC members (2009-2014).

\begin{tabular}{|c|c|}
\hline Type of accomplishment & Details \\
\hline Internships & $\begin{array}{l}2 \text { students taking the Advanced Pediatric Nutrition Elective went on to obtain internships through the } \\
\text { American Society of Nutrition }\end{array}$ \\
\hline Posters & $\begin{array}{l}>10 \text { posters presented by involved SNAAC members at notable forums including Weight of the Nation } \\
\text { in 2012, Experimental Biology, and John McCahan Educational Day at BUSM }\end{array}$ \\
\hline Presentations & $\begin{array}{l}>5 \text { presentations at Experimental Biology and John McCahan Educational Day at BUSM. Most notably, } \\
\text { one SNAAC leader was invited to speak at the Bipartisan Policy Center's forum entitled "Teaching } \\
\text { Nutrition and Physical Activity in Medical School: Training Doctors for Prevention-Oriented Care" in } \\
\text { Washington DC }\end{array}$ \\
\hline Publication & $\begin{array}{l}\text { Student-written manuscript entitled "A Novel Nutrition Medicine Education Model: the Boston } \\
\text { University Experience" published in Advances in Nutrition [29] }\end{array}$ \\
\hline Participation & $\begin{array}{l}\text { SNAAC members have been invited to participate in the New England Summit of Nutrition Medicine } \\
\text { Education (2011), the Institute of Medicine Nutrition Meetings (2013), and the Bipartisan Policy } \\
\text { Center's Forum on Nutrition and Physical Activity in Medical School (2014) }\end{array}$ \\
\hline Awards & Two students received "Best Student Presentation" at BUSM’s John McCahan Educational Day \\
\hline
\end{tabular}

in Medicine (NIM) curriculum for medical students and residents [23]. This online program contains 29 modules that can be incorporated into a 4 -year medical school curriculum. A handful of these modules have been used by many US Medical Schools [23, 24] and residencies [25] with encouraging results.

However, increasing nutrition knowledge alone is insufficient to develop competent clinicians. SNAAC has a novel approach to nutrition education reform by providing both formal curricular development and extracurricular programming that focuses on development of practical knowledge and skills. Skills such as motivational interviewing and obtaining a dietary history can be taught and practiced through events such as the DI/MS match or through early shadowing experiences in the NFL clinic. This is in line with the findings from Vetter et al., who suggested placing more emphasis on nutrition skills teaching in medical education [9]. Furthermore, by participating in activities such as the SNAP challenge, students gain a more practical understanding of the barriers to healthy eating many patients face. This allows future clinicians to appreciate the difficulties of implementing nutrition counseling in a clinical setting.

SNAAC is set apart from other student groups by its focus on interdisciplinary collaboration and education. With 
"health care reorganizing around high-functioning teams" composed of multidisciplinary providers [26, 27], collaborative skills are crucial for future physicians. These skills include the ability to work on multidisciplinary teams as well as early and appropriate referral to other health care professionals [28]. SNAAC has been successful in creating a number of partnerships with students and faculty from a variety of professional backgrounds, including registered dietitians, social workers, and case managers. Experiences with successful interdisciplinary partnerships, such as through the DI/MS match and the pediatric weight management clinic, help medical students better understand roles within a care team, as well as appreciating the expertise of their fellow health care professionals.

\section{Limitations}

SNAAC faces multiple barriers related to funding, leadership, and program continuity, as well as faculty availability. Limited funding currently comes from the medical school and faculty grants. While grant writing can be a useful exercise for some students, it can shift the focus away from the development of and participation in SNAAC programming activities. Due to academic time constraints, student participation is often limited to the preclerkship years of medical school. This results in a fast rate of leadership turnover and may affect program opportunities and achievements. SNAAC is currently guided by a small diverse group of nutrition professionals interested in promoting student medical nutrition education and training. Therefore, developing a network of student nutrition interest groups could open up additional opportunities and resources by increasing the number of students and pool of mentoring faculty interested in nutrition and available to collaborate.

\section{Future Directions}

The success of SNAAC's nutrition initiatives can best be attributed to several factors, including but not limited to (1) support from the medical school administration for curricular changes and student interest groups; (2) faculty involvement in curricular changes and mentoring students; (3) funding for select activities; and (4) student professional development. Future directions for SNAAC include continuing to develop medical nutrition programs and improving the curriculum at BUSM, participating in research, and creating a regional network of student nutrition interest groups to facilitate incorporation of effective clinical nutrition education into medical school curriculum nationally.

\section{Abbreviations}

AAMC: Association of American Medical Colleges

BMC: $\quad$ Boston Medical Center

BMSCoN: Boston Medical Student Committee on Nutrition

BUMC: Boston University Medical Center

BUSM: Boston University School of Medicine

DI/MS: Dietetic intern/medical student
NAA: Nutrition Academic Award

NFL Clinic: Nutrition and Fitness for Life Clinic

NIM: Nutrition in Medicine

SNAAC: Student Nutrition Awareness and Action

Council

SNAP: $\quad$ Supplemental Nutrition Assistance Program

VIG: $\quad$ Vertical Integration Group.

\section{Disclosure}

Cynthia Schoettler has obtained the M.P.H. degree, and was a medical student at Boston University School of Medicine at the writing of this paper; Jennifer N. Lee, was also a medical student at Boston University School of Medicine at the writing of this paper; Kathy A. Ireland, M.S., R.D., LDN, degrees holder, Clinical Dietitian and Coordinator, Nutrition and Fitness for Life Program, Boston Medical Center, Instructor of Pediatrics at Boston University School of Medicine; Carine M. Lenders, M.D., M.S., and Sc.D., degrees holder, is an Associate Professor of pediatrics at Boston University School of Medicine, Director of the Division of Pediatric Nutrition Support Services, Medical Director, Nutrition and Fitness for Life Program, and Physician Scientist at the Division of General Academic, Pediatrics Department of Pediatrics, Scientist Boston Medical Center.

\section{Conflict of Interests}

The authors declare that there is no conflict of interests regarding the publication of this paper.

\section{Acknowledgments}

The authors wish to thank Dr. Douglas H. Hughes, Associate Dean of Academic Affairs, for his support, as well as Dr. John Wiecha, Assistant Dean for Academic Affairs. The authors would also like to thank Dr. John Polk, Assistant Dean, and the BUSM Wellness Committee for their support and partnership. Former and current leaders of SNAAC have been invaluable in the creation and propagation of this novel student group. Special thanks is necessary for the student group founders, Hannah Milch and Ashley Decker, as well as Flint Wang, Stephanie Feldman, and Kaitlin Peace for their contributions to SNAAC and in editing this paper. The authors would also like to thank Kathleen Young, Ph.D., M.P.H., for her help in editing this paper. Furthermore, the authors would like to thank Joan Salge-Blake, MS, RD, LDN, Clinical Associate Professor, and Laura Judd, MS, RD, at the BU Sargent College, Boston, for their assistance with the DI/MS match as well as speaking at various events. The authors also wish to acknowledge clinicians from the Nutrition and Fitness for Life Clinic, the Grow Clinic, and the Pediatric Nutrition Support Services for their excellent clinical mentorship. They also thank Aaron Manders, M.S., R.D., LDN, for his input. Thanks are also due to the key faculty on the Nutrition Vertical Integration Group for their support and work with SNAAC students: Drs. Apovian, Fried, Harvey, Lamorte, Levine, Marino, Rao, Siegel, Stanfield, Marino, and 
Ms. Phoebe and Oliver. Additionally, this project would not have been possible without financial support through grants from the New Balance Foundation and the Allen Foundation to the Nutrition and Fitness program at Boston Medical Center, as well as additional support from Boston University School of Medicine, the Boston University Student Committee on Medical Student Affairs, the Boston University School of Medicine Wellness Program, and the NIH funded Boston Nutrition and Obesity Research Center (P30 DK46200).

\section{References}

[1] J. M. McGinnis and W. H. Foege, "Actual causes of death in the United States," The Journal of the American Medical Association, vol. 270, no. 18, pp. 2207-2212, 1993.

[2] Centers for Disease Control and Prevention, "Health plan implementation of U.S. Preventive Services Task Force A and B recommendations-Colorado, 2010," Morbidity and Mortality Weekly Report, vol. 60, no. 39, pp. 1348-1350, 2011.

[3] E. S. Ford, M. M. Bergmann, H. Boeing, C. Li, and S. Capewell, "Healthy lifestyle behaviors and all-cause mortality among adults in the United States," Preventive Medicine, vol. 55, no. 1, pp. 23-27, 2012.

[4] S. McGuire, "Institute of Medicine. 2012. Accelerating progress in obesity prevention: solving the weight of the nation. Washington, DC: the National Academies Press," Advances in Nutrition (Bethesda, Md.), vol. 3, no. 5, pp. 708-709, 2012.

[5] L. C. McGuire, T. W. Strine, C. A. Okoro, I. B. Ahluwalia, and E. S. Ford, "Healthy lifestyle behaviors among older U.S. adults with and without disabilities, Behavioral Risk Factor Surveillance System, 2003," Preventing Chronic Disease, vol. 4, no. 1, article A09, 2007.

[6] P. E. Smith and A. E. Smith, "High-quality nutritional interventions reduce costs," Healthcare Financial Management, vol. 51, no. 8, pp. 66-69, 1997.

[7] J. L. Kraschnewski, C. N. Sciamanna, H. L. Stuckey et al., "A silent response to the obesity epidemic: decline in US physician weight counseling," Medical Care, vol. 51, no. 2, pp. 186-192, 2013.

[8] K. M. Kolasa and K. Rickett, "Barriers to providing nutrition counseling cited by physicians: a survey of primary care practitioners," Nutrition in Clinical Practice, vol. 25, no. 5, pp. 502-509, 2010.

[9] M. L. Vetter, S. J. Herring, M. Sood, N. R. Shah, and A. L. Kalet, "What do resident physicians know about nutrition? An evaluation of attitudes, self-perceived proficiency and knowledge," Journal of the American College of Nutrition, vol. 27, no. 2, pp. 287-298, 2008.

[10] L. M. Gramlich, D. L. Olstad, R. Nasser et al., "Medical students' perceptions of nutrition education in Canadian universities," Applied Physiology, Nutrition and Metabolism, vol. 35, no. 3, pp. 336-343, 2010.

[11] R. L. Weinsier, J. R. Boker, E. B. Feldman, M. S. Read, and C. M. Brooks, "Nutrition knowledge of senior medical students: a collaborative study of southeastern medical schools," American Journal of Clinical Nutrition, vol. 43, no. 6, pp. 959-968, 1986.

[12] D. M. Irby, M. Cooke, and B. C. O'Brien, "Calls for reform of medical education by the Carnegie Foundation for the advancement of teaching: 1910 and 2010," Academic Medicine, vol. 85, no. 2, pp. $220-227,2010$.
[13] J. Frenk, L. Chen, Z. A. Bhutta et al., "Health professionals for a new century: transforming education to strengthen health systems in an interdependent world," The Lancet, vol. 376, no. 9756, pp. 1923-1958, 2010.

[14] A. V. Blue, M. Mitcham, T. Smith, J. Raymond, and R. Greenberg, "Changing the future of health professions: embedding interprofessional education within an academic health center," Academic Medicine, vol. 85, no. 8, pp. 1290-1295, 2010.

[15] D. R. Bridges, R. A. Davidson, P. S. Odegard, I. V. Maki, and J. Tomkowiak, "Interprofessional collaboration: three best practice models of interprofessional education," Medical Education Online, vol. 16, p. 6035, 2011.

[16] O. Karnieli-Miller, T. R. Vu, R. M. Frankel et al., "Which experiences in the hidden curriculum teach students about professionalism?" Academic Medicine, vol. 86, no. 3, pp. 369-377, 2011.

[17] L. Young, P. Baker, S. Waller, L. Hodgson, and M. Moor, "Knowing your allies: medical education and interprofessional exposure," Journal of Interprofessional Care, vol. 21, no. 2, pp. 155-163, 2007.

[18] C. P. MacDonnell, S. V. Rege, K. Misto, R. Dollase, and P. George, "An introductory interprofessional exercise for healthcare students," The American Journal of Pharmaceutical Education, vol. 76, no. 8, article 154, 2012.

[19] E. H. Spencer, E. Frank, L. K. Elon, V. S. Hertzberg, M. K. Serdula, and D. A. Galuska, "Predictors of nutrition counseling behaviors and attitudes in US medical students," The American Journal of Clinical Nutrition, vol. 84, no. 3, pp. 655-662, 2006.

[20] K. Y. Foster, N. S. Diehl, D. Shaw et al., "Medical students' readiness to provide lifestyle counseling for overweight patients," Eating Behaviors, vol. 3, no. 1, pp. 1-13, 2002.

[21] Comittee on Nutrition in Medical Education, Food and Nutrition Board, Comission on Life Sciences, and National Research Council, Eds., Nutrition Education in U.S. Medical Schools, National Academies Press, 1985.

[22] K. Ireland, E. Keefe, J. Robins, and C. Lenders, "Evaluation and teaching: nutrition education and knowledge of medical students," in Presented at the Experimental Biology, San Diego, Calif, USA, April 2014.

[23] K. M. Adams, M. Kohlmeier, M. Powell, and S. H. Zeisel, "Nutrition in medicine: nutrition education for medical students and residents," Nutrition in Clinical Practice, vol. 25, no. 5, pp. 471480, 2010.

[24] K. M. Adams, M. Kohlmeier, and S. H. Zeisel, "Nutrition education in U.S. medical schools: latest update of a national survey," Academic Medicine, vol. 85, no. 9, pp. 1537-1542, 2010.

[25] B. J. Kaplan, C. Karkowsky, M. Kohlmeier, A. K. Dayal, C. Chazotte, and E. Landsberger, "Nutrition in medicine: effectiveness of a web-based curriculum for obstetrics and gynecology residents," The FASEB Journal, vol. 27, p. 47, 2013, Meeting Abstract Supplement.

[26] P. M. Kris-Etherton, S. R. Akabas, C. W. Bales et al., "The need to advance nutrition education in the training of health care professionals and recommended research to evaluate implementation and effectiveness," The American Journal of Clinical Nutrition, vol. 99, no. 5, pp. 1153S-1166S, 2014.

[27] M. Rhea and C. Bettles, "Future changes driving dietetics workforce supply and demand: future scan 2012-2022," Journal of the Academy of Nutrition and Dietetics, vol. 112, no. 3, supplement, pp. S10-S24, 2012. 
[28] C. M. Lenders, D. D. Deen, B. Bistrian et al., "Residency and specialties training in nutrition: a call for action," The American Journal of Clinical Nutrition, vol. 99, no. 5, pp. 1174S-1183S, 2014.

[29] C. M. Lenders, K. Gorman, H. Milch et al., "A novel nutrition medicine education model: the Boston University experience," Advances in Nutrition, vol. 4, no. 1, pp. 1-7, 2013. 

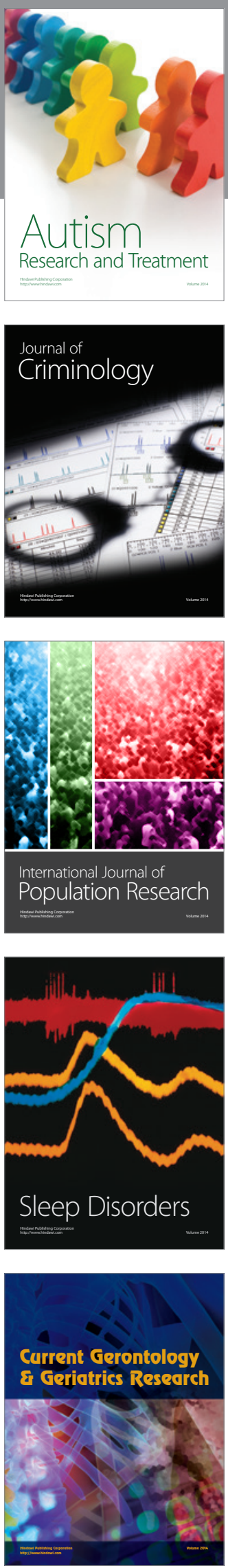
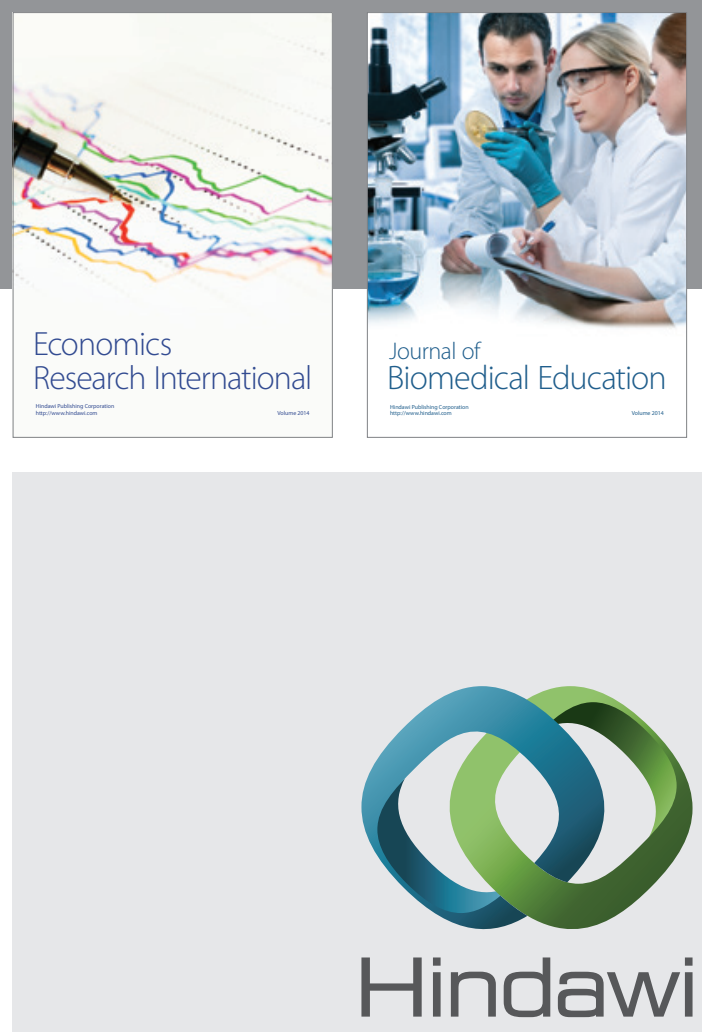

Submit your manuscripts at

http://www.hindawi.com
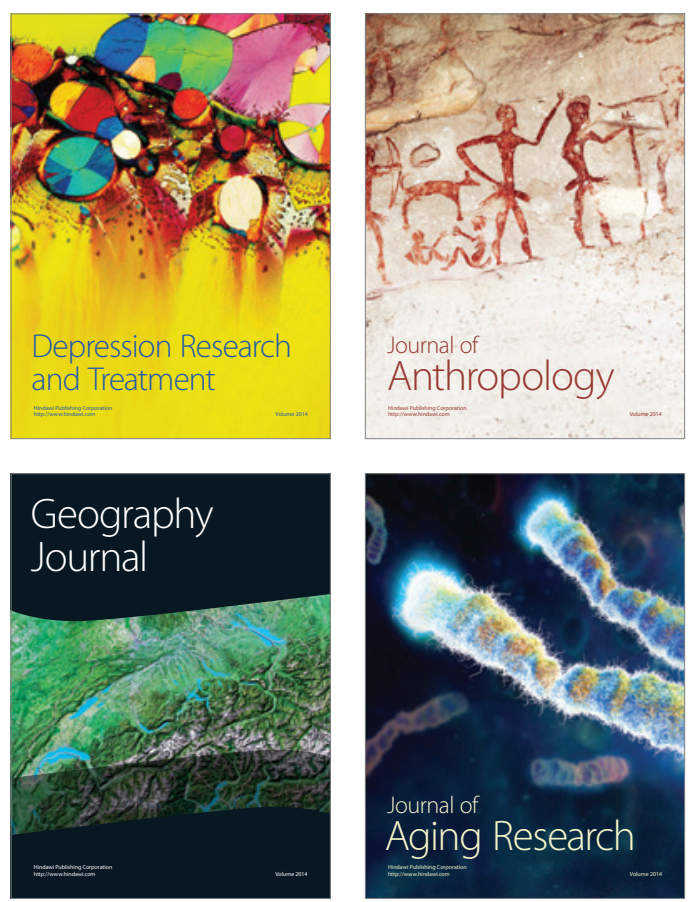
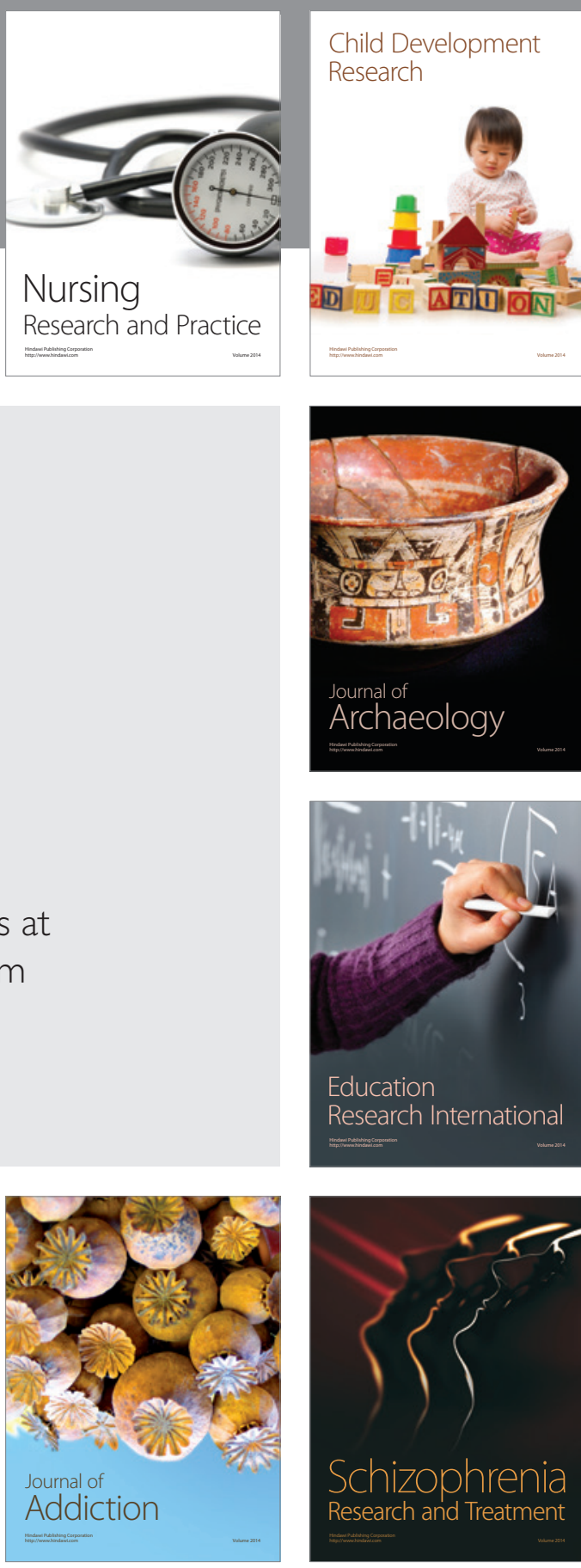

(D)
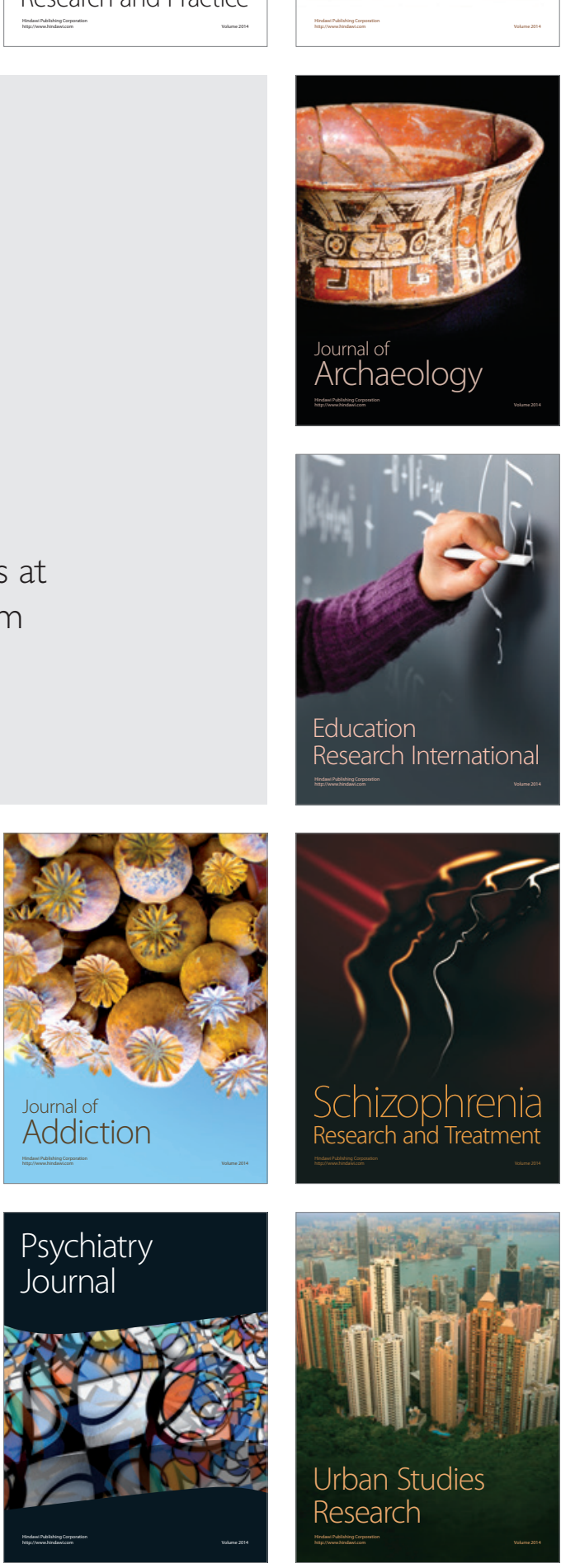